\title{
"SATISFIED AND/OR DISSATISFIED?" THE EXPERIENCE-BASED PERCEPTIONS OF SOCIAL WORK STUDENT CUSTOMERS OF STUDYING AT AN OPEN AND DISTANCE-LEARNING UNIVERSITY
}

\section{Nicky Alpaslan, George Angelopulo, Rinie Schenck}

\section{INTRODUCTION}

Because of their core business, institutions of higher education should be regarded as "service industries" (Chen, 2009:77; Sander, Stevenson, King, \& Coates, 2000:309). In terms of their objectives, these institutions' primary concerns are threefold:

- to promote individuals' academic development by way of providing in-depth knowledge and skills through teaching and learning;

- to develop new knowledge through vigorous research and the dissemination of research findings for the benefit of society;

- to render community services to society by means of consultation and engaging in community-orientated service activities (Chen, 2009:77; Maliyamokono in Higgs \& Van Wyk, 2006:87).

When labelling institutions of higher education as "service industries", the consumers of services of such higher institutions can no longer only be regarded as "students" but should be viewed as "customers". They are customers who seem to be well informed about their rights as consumers, who demand effective and quality services, who voice their concerns and dissatisfaction through formal and informal channels (i.e. in communications to University authorities as well as through public demonstrations and in the media and on social networks (Sander et al., 2000:309)). As an example, one article in the printed media comes to mind (i.e. "Unisa students march to protest high fees, service" by Tsabeng Nthite in The Pretoria News on 23 September 2006:3).

Perceiving students as customers of higher education makes it an urgent necessity for such institutions to focus on what the customers really need, together with concerted and continuous efforts towards rendering quality service delivery in order to create experiences that will be perceived as satisfying by students as customers. This calls for higher education institutions to replace what was, according to Tricker, Rangecroft and Long (2005:185), "a supplier-driven, take-it-or-leave-it model" in the past with a new model we would like to frame as "a societal needs-based, customer-informed and coconstructed model". This train of thought is endorsed by Sander et al. (2000:309), who wrote: "Higher Education typically adopted an 'inside out' approach - with us on the inside assuming we know what students look for and want from Higher Education. However, successful service industries have been shown to think 'outside in'. They research what customers expect of the service and then work to provide the service that meets those of customer expectations". 
Against this backdrop of viewing institutions of higher education as a "services industry" and its consumers as "customers", the phenomenon of "student/customer satisfaction" - which can be described as, among other things, a short-term attitude based on the evaluation of their experience with an education service supplied (Elliot \& Healy in García-Aracil, 2009:2) - needs to be placed on the agenda for debate and research in the context of open and distance learning (ODL).

This suggestion is endorsed by Gaskell (2009:193), who proposes that such debates and research endeavours should be focused on what student-customers' expectations are, how they perceive the services both onsite and online, and their general satisfaction with the service provided as "the limited amount of research on this topic suggests that student satisfaction is a complex yet poorly articulated notion that is influenced by a wide variety of contextual factors which are not intrinsically related to the quality of teaching [only]" (Brennan \& Williams in Gaskell, 2009:193; García-Aracil 2009:2). Gibbs (in Gaskell, 2009:193) concurs and points out an interesting fact (based on student satisfaction surveys conducted in ODL contexts in the United States) that while students in general appear to be satisfied with most aspects of teaching in almost all contexts, these positive responses reveal little about the students' satisfaction on the quality of teaching in relation to specific courses.

Being made aware of the latter, we want to divert the focus of the discussion to social work education offered within an ODL context. Offering social work education programmes through ODL has increased worldwide in recent decades (Oliaro \& Trotter, 2010:329). Despite this increase, Collins (2008:436) mentions that distance education has been, and continues to be, criticised as mode for teaching social work, which has provoked a considerable debate amongst social work educators in recent years, with critics and proponents adding up in almost equal measure.

The opponents against teaching social work programmes through ODL use the following as their main and common arguments.

- Historically, social work education was premised on the philosophy that training students towards becoming social workers required quality classroom interactions (Banks \& Faul, 2007:780). ODL-based social work training and education consequently tend to deprive students of the necessary prospects for personal contact, opportunities to receive feedback and to develop communication skills and a professional self through observation and modelling (Askeland \& Payne, 2007:167; Banks \& Faul, 2007:780-781). They are short-changed in terms of group involvement, relationships and socialisation (in order for them to become knowledgeable in cultural diversity), and this evokes the feelings of isolation being experienced by students (Oliaro \& Trotter, 2010:330).

- While ODL attests to being effective for providing and transmitting theoretical knowledge, its effectiveness in providing optimal opportunities to assist students to learn and practise practical social work skills, which is paramount for them in making the transition from passive learners to active professionals (Royce in McFall \& Freddolino, 2000:296) remains questionable (Collins, 2008:432). 
- Training students through ODL to become social workers conjures up terms like "masses of students", "mechanistic", "mass production" and "assembly line" (Collins, 2008:422). This results in an added demand being placed on social work practice for more social work practical work placement settings and contributes to unreasonable pressure being placed on already stretched systems (Collins, 2008:424).

- Both the train of thought and fear persist that employers may view a social work qualification obtained through ODL as "second-class" (Callahan \& Wharf, 1989; Oliaro \& Trotter, 2010:330) and inferior to a similar qualification obtained through the traditional and mainstream mode of social work education.

- ODL demands time, effort, energy, skills, knowledge and staff resources, and requires exhausting logistical arrangements and long distance problem-solving to be effective. These are added to the many other institutional pressures faced by "traditional" social work educators (Collins, 2008:424; McFall \& Freddolino, 2000:294).

The proponents for the training of students through ODL towards becoming social workers in general provide the following arguments to justify their cause.

- ODL promotes social justice as it affords an opportunity to obtain a social work qualification to mature, employed, part-time, physically and geographically isolated students, as well as students with a disability and those who lack resources and do not meet the prerequisite entry requirements to gain access to the traditional learning settings (Collins, 2008:430; Oliaro \& Trotter, 2010:340;York, 2008:162).

- ODL values "individuation", "flexibility" and is "learner-centred focused". ODL enables students as individuals to follow their own educational pursuits by providing the ultimate in "individualistic timing and localisation" in that students can study in a variety of locations (i.e. from home and/or work) at a time convenient to them with some degree of self-determination and through self-regulated learning (Artino, 2008:261; Collins, 2008:427,430).

- While the effectiveness of ODL training provided to students to become social workers has been, and continues to be, questioned by critics in the field of social work education, studies conducted (referred to below) reported positive outcomes for distance-learning programmes. In spite of the fact that research findings on the effectiveness of ODL social work programmes in Britain seem to be lacking (Collins, 2008:426), data available from studies conducted in the USA point to the following:

- The educational experiences and achievements of ODL social work students are equivalent to those of traditional students and the same grades are achieved by both groups (Collins, 2008:426; Haga \& Heitkamp, 2000:317; Potts \& Hagan, 2000:132;143);

\footnotetext{
1 Self-regulated learning has been defined by Pintrich (in Artino, 2008:261-262) as "an active constructive process whereby learners set goals for their learning and then attempt to monitor, regulate and control their cognition, motivation and behaviour, guided and constrained by their goals and contextual features of the environment".
} 
- ODL social work students indicate satisfaction levels at least equivalent to those obtained by traditional classroom teaching (Haga \& Heitkamp, 2000:313; Potts \& Hagan, 2000:132; Collins, 2008:426).

In the study undertaken by Oliaro and Trotter (2010:329) amongst a cohort of recent graduates from Monash University BSW course, it was found that off-campus social work education appeared to meet the needs of a particular group of students (i.e. older students who are married with children, employed and living some distance from a residential university).

Whilst the views and arguments against and in support of social work training through the vehicle of ODL were clearly noted in the literature (referred to above), we detected in the former a unified call for more systematic, qualitative and quantitative research about and on the evaluation of ODL in social work education and students' satisfaction with distance offerings (Collins, 2008:427; Haga \& Heitkamp, 2000:310; Oliaro \& Trotter 2010:334). This call for research found in the literature focusing specifically on social work education in the context of ODL is sanctioned in the general literature on student satisfaction with ODL. Sahin and Shelley (2008:217,221) emphasise the importance of research into student learning, as without research investigating undergraduate students' perceptions and experiences about their distance education courses, it will be difficult to meet their needs and improve the students' ODL experiences and satisfaction. Walker and Kelly (2007:310) concur and point to the fact that online and ODL universities that are in the business of offering entry-level to doctoral qualifications should continuously grapple with the question: "How are we doing?"

This question, coupled with the call for more systematic, qualitative and quantitative research about and on the evaluation of social work education in the ODL context, served as motivation for embarking on a research project with the aim of exploring and describing the perceptions of Unisa's social work students as customers of their social work studies at Unisa.

This research project enhanced and furthered the aim of the Department of Social Work at Unisa to compile, through research, a body of knowledge on their students' or customers' personal and learning-related situations in the context of open and distance learning, and their levels of satisfaction in relation to studying social work at an open and distance learning university (Alpaslan, 2010a; Alpaslan, 2010b; Alpaslan \& Lombard, 2011; Alpaslan, 2012; Lawlor, 2008; Lintvelt, 2008; Schenck, 2009; Wade, 2009).

\section{RESEARCHMETHODOLOGY}

In an attempt to realise the aforementioned aim, an explorative and descriptive research design and Q-methodology as research method were employed.

In the social sciences a large proportion of research is conducted with the aim of exploring a topic or to start a knowledge-building process on a "new topic" or learn more about issues where little is known (Babbie \& Mouton, 2011:79; Neuman, 
1997:17). Subsequent to the exploration of a topic, a descriptive design can be employed with the intention to provide a detailed description of what was explored. In essence, the researcher explores and then describes what was explored and/or observed (Babbie \& Mouton, 2011:79; Neuman, 1997:20).

Q-methodology, as a research method, has its roots in the psychology and work of William Stephenson (1902-1989), a British physicist and psychologist who introduced the approach in 1935 as an alternative and/or ancillary to the traditional qualitative and quantitative research methods (Angelopulo 2009:21; Ellingsen, Størksen \& Stephens, 2010:395, 396; Petit dit Dariel, Wharrad \& Windle, 2010:60). Q-methodology aims to study subjectivity (Petit dit Dariel et al., 2010:60) and is concerned with the individual viewpoints of participants, as it wishes to provide them with the opportunity to express their opinions about a topic not hypothesised by the researcher (Dziopa \& Ahren, 2011:39). In endeavouring to study and analyse subjective viewpoints, through employing Q-methodology, a combination of techniques inherent to the qualitative and quantitative approaches to research is employed (Akhtar-Danesh, Dehghan, Morrison \& Foneska, 2011:68-69), contributing to the trend not to classify Q-methodology along the qualitative-quantitative divide (Petit dit Dariel et al., 2010:60), but rather to describe it as "qualiquantilogical" by nature (Angelopulo, 2009:22; Dzopa \& Ahren, 2011:39). In the literature (Angelopulo, 2009:23-27; Dziopa \& Ahren, 2011:39-42; Ellingsen et al., 2010:397-404) Q-methodology as research method or technique (Dziopa \& Ahren, 2011:39) is implemented sequentially according to the five steps described below.

Step 1: Identifying a concourse on the topic of interest: This step entails focused communicating about, and collecting all possible "viewpoints" or "vantage points" on, the issue or topic of interest in order to constitute the "concourse" (Ellingsen et al., 2010:397). In respect of the research project reported on here (hereafter referred to as the social work study), the research team ${ }^{2}$ did not, as suggested in the literature (Ellingsen et al., 2010:397), engage in interviewing purposively selected participants with the intention to identify a concourse, but took on, condensed and adapted the existing 49item Q-sample (i.e. a representative set of statements from a concourse) as developed by Angelopulo (forthcoming) for a study undertaken earlier with the aim to report on students' perceptions of the factors that govern enrolment and retention in the academic programmes of the Department of Communication Science at the University of South Africa. In condensing and adapting the existing Q-sample for the social work study, the research team omitted some of the statements not applicable to social work and replaced a few statements in the adopted Q-sample with social work-related specific statements (based on the input from the social work professors who formed part of the research team). With reference to the remaining adopted items in the adopted Q-sample, the term "Communication Studies" was replaced with "Social Work". For example: the item reading: "The Department Communication Studies gives high-quality responses to

2 This research team was comprised of two professors from the Department of Social Work and one from the Department of Communication Sciences at Unisa. 
enquiries" was rephrased as: "The Department of Social Work gives high-quality responses to enquiries".

Step 2: Developing a representative set of statements ( $Q$-sample): In view of executing this step in the Q-methodology process, the researcher can, as suggested by Shinebourne and Adams (2007:104), gather items for inclusion in the Q-sample from various sources: from direct quotations and themes from the interviews conducted with participants; from statements originating from academic literature and the popular media; or can implement or take on an existing ready-made Q-sample. For this social work study, as mentioned under Step 1 above, Angelopulo's (forthcoming) Q-sample comprised of 49 items was adopted, shortened and adapted for the purpose of this study.

All the items were stated in the positive and focused on the following key marketing dimensions of service quality:

- professionalism and skills as technical competence or dimensions of quality;

- reputation, credibility and image;

- accessibility and flexibility of the service industry and department;

- its reliability and trustworthiness and service recovery (i.e. the ability to recover from service problems);

- and its "servicescape" (i.e. the environment in which the service is offered and consumed) (Angelopulo, 2009:24; Angelopulo, forthcoming).

Before implementing the Q-sample, it was pretested.

Step 3: Specifying the participants for the study and defining the conditions of instruction: In a Q-study the participants engaged in the study are referred to as the "person sample" or "P-set" and are drawn from a "P-sample" or a "population sample" (Angelopulo, 2009:26; Ellingsen et al., 2010:398). Based on the fact that the aim with a Q-study is to obtain subjectivity by revealing the number and nature of different points of view (or perceptions) that exist within a group related to the topic of interest (Ellingsen et al., 2010:398-399), smaller sample numbers are drawn from the P-sample (i.e. the population sample) employing sampling techniques normally used in qualitative research (Petit dit Dariel et al., 2010:67). The person sample might, for example, be purposively selected. With purposive sampling the researcher will purposely or intentionally seek out participants for inclusion in the sample based on the fact that they are knowledgeable about the topic of interest and able to articulate their viewpoints (Donalek \& Soldwisch, 2004:356).

In this social work study, the P-sample (or population) was comprised of all social work students enrolled at the Department of Social Work at Unisa in 2011 who were listed as having a myLife@Unisa e-mail address ${ }^{3}$ on myUnisa ${ }^{4}$. The 35 item Q-sample was sent

\footnotetext{
3 myLife@Unisa is Unisa's student e-mail system and its primary use is for purposes relating directly to education and for correspondences and communication; it is considered as an official communication standard between the students and the University.
} 
to each student registered for the core social work modules from levels one to four and the students enrolled for postgraduate studies within the Department with a myLife@Unisa e-mail address. The conditions of instruction entailed the following: Once the participant opened the e-mail message entitled: "Department of Social Work Survey" the following message popped up: "The Department of Social Work wants to find out what you think of your Social Work studies at Unisa. Please give us your views by completing the survey. The process takes 10-15 minutes. Click the 'NEXT' link: http://www.unisa.ac.za/SocialWorkSurvey2011 to get to the assessment." Upon clicking this link, an ethical statement appeared which the participant had to read prior to getting to the Q-sample where he or she had to respond to each of the items or statements on a 9-point Likert scale ranging from "strongly agree" to "strongly disagree". The students were also informed about this survey by sending out an SMS to each of them. On the Qsample provision was made allowing for free and additional comments related to the Qset.

Step 4: Administering the $\boldsymbol{Q}$ sort: In terms of this step, the Q-sorting procedure is conducted in the presence of the researcher. The statements in the Q-sample are presented to the participants on cards, one statement per card and randomly numbered (Angelopulo, forthcoming; Ellingsen et al., 2010:398). The participants need to sort these cards on a grid that allows placement in order of some continuum ranging from "strongly agree" on the one side to "strongly disagree" on the other side (Angelopulo, forthcoming).

In this social work study the administering of the Q-sort discussed in the previous paragraph was impossible because of the dispersion of the participants (i.e. distanteducation students) and the Q-sort was conducted online by requesting the participants to execute the instructions referred to under Step 3 above. A total of 1364 students participated in this study.

Step 5: Factor analysis and interpretation: This final step consists of analysing and interpreting the results. For the purpose of factor analysis a PQMethod software programme that can be employed where each participant's Q-sorts are entered into the programme and the Q-sorts are analysed using a by-person factor analysis (Watts \& Stenner in Ellingsen et al., 2010:400).

In this social work study the final step of factor analysis of the participants' Q-sorts will be reported in another publication.

The research findings to be presented in the next section of this paper were deduced from the process of data analysis conducted on the free comments that the participants offered in addition to statements in the Q-set.

4 On the Unisa's Intranet the "myUnisa" is described as follows: "myUnisa is a web-based system for academic collaboration and study-related interaction. The system has been developed to supplement and enhance academic interaction and improve communication between Unisa and its students as well as to provide opportunity for engagement amongst students" (i.e. on the discussion forums). 
The textual, non-numerical and unstructured nature of the free comments provided by the participants dictated that we needed to follow a qualitative data analysis process. Qualitative data analysis in essence entails working with data "which are textual, nonnumerical and unstructured, organising it, breaking it into meaningful units, synthesising it, searching for patterns, discovering what is important and what is to be learned, and deciding what to tell others" (Bogdan \& Bilken, 1982:145). In assisting us to analyse the free comments totalling 125 pages (typed in landscape format, in $1 \frac{1}{2}$ line spacing and 12-point font size), we used the eight steps for analysing qualitative data as proposed by Tesch (in Creswell, 2009:186).

In order to enhance the trustworthiness of the research findings deduced specifically from the free and additional comments provided by the participants, we employed triangulation of data sources which by definition means combining the perceptions of more than two participants to underscore the identified themes (presented below) (McBrien, 2008:1288; Shenton, 2004:66). To enhance the credibility of the findings, and based on the suggestion by Shenton (2004:64), we employed a widely-accepted qualitative data analysis protocol (i.e. the eight steps proposed by Tesch in Creswell, 2009:186) to ensure that the empirical evidence to be reported is representative of reality. Additionally, we engaged the members of the research team and fellow colleagues to critically read the section on the research findings and our interpretation of them as this provided a helpful opportunity to challenge and critique the robustness of the themes we identified (McBrien, 2008:1287).

\section{DISCUSSION OF THE FINDINGS}

The research findings presented in the next part of this paper resulted from the analysis of free and additional comments that the participants made in the space provided following the Q-set.

The discussion on the research findings is presented under the following sub-headings:

- The biographical profile of the participants;

- A discussion on the themes (and sub-themes) that emerged from the processes of data analysis. This discussion is supported by narratives from the transcribed interviews and complemented by a literature control.

\section{The biographical profile of the participants}

A total of 1364 students participated in this study and the table below provides a biographical profile of the participants.

\section{TABLE 1}

BIOGRAPHICAL PROFILE OF THE PARTICIPANTS

\begin{tabular}{|c|c|l|c|l|c|}
\hline \multicolumn{2}{|c|}{ Gender } & \multicolumn{1}{c|}{ Race } & N & Occupation & N \\
\cline { 1 - 4 } Male & Female & Black & 1171 & Employed & 960 \\
\hline N & $\mathrm{N}$ & Coloured & 39 & Unemployed & 404 \\
\cline { 1 - 3 } & 1131 & Indian & 18 & \multicolumn{2}{|}{} \\
\cline { 1 - 3 } & White & 136 &
\end{tabular}


Looking at the table above it becomes clear that the majority of the participants in this study were female, which confirms the trend that social work is a "female-dominated profession" (Christie \& Kruk, 1998:25; McPhail 2004:323; Pease, 2011:406407). With reference to race, the majority of the participants were black. This phenomenon typifies Unisa's student profile, because according to Unisa's Hemis figures for 2011 on Unisa's Intranet, 69\% (or 227680 out of 328 179) of the undergraduate and occasional students registered at Unisa are from the black race group.

More than two thirds of the participants in this study indicated that they were employed whilst pursuing their social work studies at Unisa. A similar trend was noted in Lintvelt's (2008:72) research, where 40 out of 90 respondents (i.e. student social workers) indicated that they were employed whilst studying at Unisa (Alpaslan \& Lombard, 2011:436; Collins, 2008:430; Oliaro \& Trotter, 2010:340; York, 2008:162).

\section{Discussion of themes and literature control}

In this section the themes that emerged from the process of data analysis are presented and underscored by the free comments provided by the participants and complemented with a literature control.

\section{Theme: Motivations for choosing the UNISA brand as university of choice for studying towards becoming social workers}

A "brand" refers to "a name, term, sign, or symbol or any combination of them, that represents the unique benefits a company can provide through a particular product or service, in terms of attributes, value and culture" (Kotler in Wang \& Yang, 2010:177).

The motivations, deduced from the free comments, pointing to the benefits provided by Unisa and its being the "preferred brand" or the participants' university of choice in pursuing their social work studies are summarised below with direct quotations to underscore the motivations:

- Unisa is a recognised ODL university in the world, produces quality students and a Unisa qualification ensures employability

"It's one of the best recognised distance open learning university in the world and it caters for all the people in the world."

"...with my social work qualification I get at Unisa I will be able to work everywhere."

"I chose Unisa ... it has a highly respected qualification."

Unisa provides the working person an opportunity to study and caters for mature students

"... Unisa ... is an open and distance learning, so it enables them to work while they studying so that they can fulfil their needs and pay their study fees."

"Studying social work through UNISA has offered me a chance for a second career in my middle-age."

"I thank God to use Unisa to reach the dream of my heart especially at my age. Unisa you proved [to] me that it is never too late to study." 
These comments resonate in the literature, pointing to the fact that ODL promotes social justice as it affords mature, employed, part-time, physically and geographically isolated students, as well as students with a disability, with an opportunity to access tertiary education and obtain a social work qualification (Collins, 2008:430; Oliaro \& Trotter, 2010:340; York, 2008:162).

\section{- Unisa is affordable, and being ODL, it is accessible}

"I chose this institution because is affordable”... “... and reliable."

"... Unisa is good for me ... I have to register for the modules I can afford, paying for them only."

"... It offers distant learning and is ... accessible to a majority of students."

The fact that Unisa is perceived by the participants as "accessible" and "flexible" in terms of allowing students to study at their "own pace" (see the next sub-theme) ties in with key marketing dimensions as pointed out by Angelopolou (2009:24; forthcoming). The motivation for choosing Unisa as university of choice on the ground of its affordability is underscored by Kilfoil (in Schenck, 2009:299), who states that Unisa attracts a large number of students who have come straight from school because Unisa is the most affordable tertiary institution.

\section{- Unisa allows for independent study at the students' own pace}

"I like to be part of Unisa because I study at my own pace."

"I like the fact that I study independently."

In confirmation of the previous motivation and quotations provided, the literature states that ODL enables students as individuals to follow their own educational pursuits by providing the ultimate in "individualistic timing and localisation". Students can study in a variety of locations (e.g. from home and/or work) at a time convenient to them, at their own pace, and with some degree of self-determination and through self-regulated learning (Artino, 2008:261; Collins, 2008:427,430).

- Unisa provides students access to tertiary education who would otherwise not be allowed entrance to other universities as they do not meet the prerequisite entry requirements

“... the admission that Unisa gives to us people who didn't have admission to any university ... Unisa ... helps a lot of students who would not have had the opportunity to access the university. I love the strategy that Unisa uses to reach out to the less-fortunate."

"I study at Unisa because I passed my Matric with a very low symbol but Unisa did not reject me."

The literature confirms that ODL institutions such as Unisa fulfil a critical social mandate in that they allow students who would otherwise not have access to education either for financial reasons, or because of employment, or living in remote areas, or they cannot access residential universities because of a disability, or who do not meet the 
prerequisite entry requirements - access into the arena of tertiary education (Collins, 2008:430; Oliaro \& Trotter 2010:340; Unisa Self-evaluation Portfolio for the HEQC Institutional Audit, 2008:15; York, 2008:162).

The focus of the discussion shifts now to presenting the participants' experience-based perceptions of being customers of Unisa thematically. After scrutinising and analysing their free comments, we became aware of the fact that these experience-based perceptions were neither positive nor negative, and the participants were both satisfied and dissatisfied with the online, site and off-site services offered to them whilst studying at Unisa. The following quotation (one of many) points substantiates this: "I'm just a proud Unisa student and knowing that as an institution it's not possible that all of my needs and expectations can be met".

\section{THEME: The customers ${ }^{5}$ are satisfied and perceive and experience studying at UNISA as positive}

In underscoring this theme, the following comments summarise the combined voice of the participants in testifying to their experience-based satisfaction and positivity about studying at Unisa:

"Studying at Unisa is good and interesting ... Unisa, it's impressing because [it's] giving us high education on studying alone."

"According to my own point of view, there is nothing wrong with studying Social Work at UNISA because UNISA has changed my life from bottom-up..."

"... here at Unisa the service is excellent."

Aspects that were repeatedly mentioned pointing to what underlies the participants' satisfaction and positivity about Unisa are encapsulated by the following comments:

"The staff is always very friendly and helpful" and "very effective."

"... the course content is accurate and well organised."

"... I think that your examinations are fair to students."

"Unisa ... makes things easy for me through their study materials and easy access to its internet ...."

"... The communication from lectures to students is excellent."

\section{THEME: The customers are satisfied and perceive and experience studying at the department of social work as positive}

Interspersed in the participants' comments were accounts pointing to their satisfaction with and positivity about studying at the Department of Social Work. The following comments indicate the collective voice of the participants in this regard:

"Studying social work at Unisa made me feel like a qualified one on my first level."

5 Hereafter the phrase "customer" will be refer to as "social work student as customer", unless otherwise stated. 
"The Department of Social Work at Unisa is doing quite well, they know their job."

"I just want the social work department to know that I ... enjoyed the studies so much that I have decided to do as my masters".

Some of the comments above correspond with those of the respondents (i.e. fourth-level student social workers) in Lintvelt's (2008:80-81) research.

The specific factors contributing to the participants' satisfaction with the Department specifically (illustrated by way of summarising the common experiences and perceptions) were the following:

- The user-friendliness of the social work study material:

"I want [to] express how nicely the social work modules have been compiled. I find them very easy to use and really beneficial"; "the course content very much accurate and understandable", and "I loved to read my study guides it was like I had someone sitting there with me teaching me."

Fifteen of the 90 respondents in Linvelt's study $(2008: 80,118)$ also made reference to the user-friendliness of the study material.

\section{- The support from the staff in the Department:}

"I believe that the Department of Social Work caters for us and care about their student $[\mathrm{s}] . .$. " and "...the kind of support get from Department of Social Work makes learning to be easy."

- The friendliness, professionalism and efficiency of the department's staff mem bers: "... The staff members are friendly and the services they offer are perfect"; "I am pleasantly surprised by how helpful, efficient ... members of the department are”; "... I like the professionalism and the care that is shown" and "... [they] ... are highly trained people with lot of experiences as they are also social workers they teach very well."

The previously mentioned sub-themes' corresponding comments referring to the staff in the Department match the statements made by the respondents in Linvelt's research (2008:80-81), where 30 out of the 90 respondents were of the view that the Department of Social Work is the one department where lecturers go out of their way to assist students when they need help.

\section{- Tutorial classes and workshops are helpful:}

"... doing workshops helps a lot to gain experiences about the work of the social worker"; "... the workshops ... helped me in my learning process", and "The tutorials are easy to understand and make studying easier."

- Easy access to Unisa and lecturers: "...myUnisa is very helpful and the lectures are communicating with is via myLife. It's easy to get access to lectures at Unisa and they are helpful", and "Good communication ... via myLife, SMS, and myUnisa." 
The following comment sums up the previous two themes illuminating aspects contributing to the customers' satisfaction about Unisa and its Department of Social Work:

"It has been a very valuable learning experience studying Social Work at Unisa generally I have been satisfied with the service I was given as a student and over the past five years have experienced few problems but these were easily resolved."

\section{THEME: Aspects related to UNISA that the customers are dissatisfied about and perceive negatively}

The aspects, related to Unisa specifically, that the participants felt unhappy about and perceived in a negative light are presented next as sub-themes.

\section{- Customers'dissatisfaction relating to registration and lack of guidance on subject choices at registration}

While prospective customers of Unisa are extensively informed that they must "apply" before "they can register", participants experience registration negatively for the following reasons:

"During registration periods it is difficult to register at the centres as it is congested, [and] the queue for registration is always long."

“... [There is] a lack of support during registration ..." “... you are just given the calendar there is no one to guide/help you" ... choose perfect subject. You find yourself doing wrong things and you have to ask your fellow student s/he will give what best for him or her so you end up repeating one thing because you didn't get exact info". Also "... the subject advisors [available]" "...sometimes they confuse you about what modules to take and which are the prerequisites. When you prepare to register for fourth level, you then discover you have been misinformed you have unnecessary modules which you need to throw away and you have modules missing and you cannot do your fourth level the way you intend."

These experiences concerning registration corresponds with the findings from Alpaslan and Lombard (2011:441) and Linvelt's studies (2008:75), and match a comment made by the Bureau of Market Research at Unisa (2010) following a study into Unisa student registration and campus perception study, stating that students perceive staff at registration as incapable of assisting with course choices relevant to career aspirations because of their lack of exposure and insight into certain highly specialised fields.

\section{- The late arrival of study material}

Reference to this sub-theme was noticed throughout the data set and the following storylines are reflective of this:

"Study Materials arriving late...”, “... and sometimes we don't receive tutorial letters on time especially for exams preparations". When the study material “... to complete the assignments or tasks ... reach us late \& we end up writing things 
that we don't understand and even copying from our friends because of the time".

In underscoring the above sub-theme and comments, 28 out of the 90 respondents in Lintvelt's study (2008:77) who were students who had registered for at least one fourthlevel module in January 2007 indicated that they experienced problems with study material. Some of them did not receive all their material in time (Alpaslan \& Lombard, 2011:441; Botha, 2011:458), while other students complained that they did not receive some of the material at all. Delays in the supply of course books were also mentioned as a reason for unhappiness amongst distance students at the University of Education, in Winneba, Ghana (Asante, 2008:70).

\section{- Assignments getting lost in the post}

In reflecting the participants' dissatisfaction in relation to this sub-theme the following supporting comments are provided: "I get frustrated when one of my assignments submitted is not received by UNISA", and "... assignments tend to get lost".

\section{- Dissatisfaction around Unisa's examinations}

Comments related to students' unhappiness with the examinations are: “... examinations, it's difficult" and "It's unfair to write major subjects/modules in succession; it means that you want us to fail and remain Unisa student for years".

\section{- Customers' dissatisfaction with Unisa's ICT services}

In summarising the communal dissatisfaction, amongst the students related to this subtheme, the following comments: "I struggle for a long time now to get myUnisa password", I struggle to log on to myUnisa, I only log on to myLife account"; [I struggle] to get my study material online”; "... myUnisa always have a problem to access it", and "Submission of assignments can be difficult due to myUnisa [being] offline".

\section{- Negative perceptions about, and dissatisfaction around, the closure of the Call Centre}

The following comments encapsulate the collective voice of the participants around the closure of the Call Centre: "...contact has not been good since the Contact centre doesn't work anymore... and we can't phone!!!! This has made Unisa an unpleasant place to study through"; "This has made it more difficult to have my enquiries replied to. I can't even get hold of the numbers I should be phoning because this system is so inefficient" and "The closure of the call centre is a disadvantage for those students who do not have access to computers as it sometimes takes a number of days to respond to the SMSs."

\section{- Dissatisfaction experienced in relation to library matters at Unisa}

Comments concerning the unhappiness experienced in terms of library matters were made along the following lines: “... we have problems with books. ... there are no books if you find a book it will be very old (year) ... there are no air-condition in the library ..."; “... we struggle to study for our exam due to unavailability of space (LIBRARY)"; 
... at rural areas ... there is a shortage of resources ... a lack of computers and libraries which affect us ...", and "libraries are too far ...."

A minority of participants in Linvelt's study (2008:75) also felt dissatisfied about the lack of books (especially at the Regional Libraries) and of space to study. Asante (2008:70) in a study amongst Basic Education Students at the University of Education, Winneba, Ghana, found that $81.3 \%$ of 268 of the participants expressed low perceived satisfaction in relation to library support in that libraries are either non-existent, or far away and ill-equipped.

- Customers' dissatisfaction with the state of facilities, lack of resources for, and lack of workshops, tutorial and discussion classes at, regional offices, and the nature of services rendered by staff at regional offices

From the comments made it became clear that "the staff@ the Bloemfontein campus is not helpful to students when registering courses" resulting in students "... registering wrong courses". They are "... not friendly and they are sloppy and even eat behind the counter even if they are not on lunch. They help you as if they are doing us a favour". Focussng on Mthatha, "the staff employed here is not knowledgeable about most of the queries presented to them".

The lack of resources at some of the regional offices was specifically referred to: “... in Polokwane we are still suffering for resources"; "... at Bloemfontein branch there are no tutorial classes, no satellite class and no group discussion"; "... "The facilities [in Durban] e.g. toilets, sometimes the lift [doesn't] work, it's overcrowded", and "The Unisa building in the CBD of Johannesburg is in a poor state and not well-maintained". The lack of resources referred to above pertaining to the Durban Regional Office of the Department of Social Work was also mentioned by the participants in Alpaslan and Lombard's (2011:443) study.

One customer stated "video conferences are just waste of time and money" and to qualify this experience-based perception the following comments: "The equipment of Unisa is not enough and good for an example the sound system during discussion classes ...the volume is very low we cannot hear correctly", and "Video conferencing is really not the best option for having class as the openness of the students is automatically not present anymore".

The aforementioned discussion focused on aspects related to Unisa that the customers are unhappy about and on which they have negative experience-based perceptions. In the discussion to follow the aspects that the customers are dissatisfied about and perceive negatively related to the Department of Social Work are presented.

\section{THEME: Aspects related to the department of social work that the customers are dissatisfied about and perceive negatively}

This theme is be presented under sub-themes and, in substantiating them, excerpts from the participants' comments are quoted in a summarised fashion to convey the shared experiences and experience-based perceptions related to this theme and its accompanying sub-themes. 


\section{- Assignment-related dissatisfactions}

The student customers' dissatisfaction about this aspect was frequently noted in the data set. The participants were unhappy about the fact that "the department of Social work delays the assignments feedback". This resulted in a commonly shared experience where "... we are writing our examination without having our assignment results and feedbacks which ... leave us not knowing where to improve". Furthermore, "... the date of submission [of assignments] constantly change ... This disadvantaged me because I had submitted mine on time and those who had late submissions benefited". Also, "...marks for assignments not posted".

The aforementioned dissatisfaction also surfaced as complaints in the studies of Botha (2011:458) and Lintvelt (2008:142) conducted amongst Unisa's social work students, as well as amongst Asante's (2008:70) distance education participant students at the University of Education, in Winneba, Ghana.

\section{- Unhappiness about the way of marking of assignments and incorrect allocation of marks}

Comments relating to this issue were noted frequently in the data set. Comments indicating their shared experiences and perceptions in this regard were:

"The answer scripts to exams are marked by different markers and thus there is not enough control of the subjectivity of the marker or his/her expertise in marking. Therefore, a good mark is not based only on the student's knowledge but is also based on luck of the draw when it comes to markers. The same applies to assignments..."

“... some lecturers provide thorough feedback on problems and assignments whilst others don't ..."

"Marks on written assignments added up incorrectly resulting in students having to resubmit assignments (at their own cost and obviously increased stress levels!)".

"... [with] written we find that some places are not marked ..."

“... Sometimes assignments are returned without comments and sometimes unmarked."

In Lintvelt's study $(2008: 81,119)$ the respondents had similar complaints to the ones mentioned above.

- Unhappiness about the non-availability of staff members (telephonically) and slow/no response to emails

This aspect was noticed the most in the data set and while a few of the participants shared the experience-based perception that some lecturers "... reply promptly to emails and voicemails", the majority had an opposite perception and experience: "Getting hold of some lecturers are near to impossible"; "Some lecturers often do not respond to emails and are seldom available telephonically"; and this challenge "... to get hold of the lecturers or course leaders and results to frustration and loneliness on the side of 
students." "Trying to call lecturers is like gamble because often the phone will ring without being answered and if answered there's sometimes a feeling that you are bothering them and you are unreasonable for not automatically knowing the answer".

The said obstacle is confirmed in the literature consulted (Alpaslan \& Lombard, 2011:442; Botha, 2011:458; Lintvelt, 2008:119) and Galusha (s.a.) is of the opinion that "the perceived lack of feedback or contact with the teacher is one of the common barriers to distance learning".

\section{- Unhappiness with the content and quality of the study material}

One participant, a first-year student, stated: "I find the study material was written for persons that are already in the field and know the terminology. I found it very difficult". Some of the participants in Alpaslan and Lombard's (2011:442) study shared the same sentiments.

Pertaining to the quality of the study material, the shared critique was: "Numerous spelling and grammatical errors in study guides resulting in it sometimes affecting the whole essence of the message" and "There are often typos, poor language use and inconsistent instructions".

\section{- Complaints around and frustrations with supervisors; workshop facilitators, workshops and tutorial classes}

The complaints concerning the workshop facilitators and supervisors can be summed up along the following lines: "Many of the workshop facilitators and supervisors are not motivated or don't know the person-centred approach"; “... are unfamiliar with the course material and are poor at facilitating; "... are not prepared”; I ... really got frustrated with workshop facilitators being so person-centred that it ended up that no work gets done because fellow students don't prepare”; “... Some of the facilitators are rude and impatient with us".

The complaints and frustrations concerning the tutorial classes and workshops were generally about the fact that there "... are no tutorial classes for social work modules and no satellite classes too" at some of the regional offices", and if they are available "... tutoring is not at the expected quality level in small towns". While tutorial classes are available to students at first level in the larger regions, "A lot of students ... are having difficulties in their second year because there are no tutorial classes". Adding to this is "... the fact that the second level students don't have workshops anymore ... we often don't know what to do with the portfolio and the failure rate is high". This aforementioned difficulty hints at the need for more workshops and corresponds with a similar request expressed by some of the second-and third-level student social worker participants in Alpaslan and Lombard's (2011:443) study. 
Another common complaint was: "The social work tutorial classes are only conducted on Saturdays ${ }^{6}$ and the classes are too big; it's hard to concentrate”, and "... we did not have enough classes to discuss the work". Some participants complained that they "... had to put in leave for these sessions", and "... while Social Work students ... are not getting enough workshops regarding our course, if we do get them, sometimes, you feel like you wasted your time being there .... I feel that when we have workshops it should be worthwhile" (Alpaslan \& Lombard, 2011:443). What frustrated some of the participants was the "... cancellation of workshops without proper notice" and changing of dates of tutorial classes and workshops: "I do not like the fact that dates for tutorials change. As a person working full time one has to plan dates a while ahead so that employers are in the know. Almost every workshop date has changed this year which is extremely frustrating".

Some participants also noted that they had to take leave to attend workshops, with the latter being "... too far from us and it costs a lot to get there" and "... we have to travel long distances" (Callahan \& Wharf, 1989:64; Lintvelt, 2008:119). Also, “...sometimes it is difficult [especially] to attend workshops on three to five consecutive days for more than six hours a day". Adding to this was another train of thought that the "... workshops are too much".

\section{- Dissatisfaction around calendar changes and rules and restrictions in relation to the number of social work modules students are allowed to register for}

The following comments provide a general summary of the students' discontent concerning this sub-theme:

"One thing I do not like about social work is the fact that it has way too many restrictions/rules such as: students are not allowed to register for more than 10 modules per year", and "The fact that Unisa is always changing the Calendar every year. That affected me because I was supposed to do 12 modules this year [referring to 2011] as was documented on the 2010 calendar and now I am doing only 10 modules because Unisa did not allow me to register that 12 module as was [stated] in the 2010 curriculum ...". Furthermore, “... when you fail one year course you can't register for the following year courses. You [are] stuck", and "Their [referring to the Department] rules ... don't allow students to take ten subjects for the last year unless you got $60 \%$ in each subject".

In support of these comments, 16 participants' in Lintvelt's study (2008:81) were dissatisfied with, amongst other things, the fact that the Department decided during their third level in 2006 that students whose average mark for Social Work is under 60\% will not be allowed to register for certain modules for the forthcoming fourth level and that

6 Deducing from some of the comments in the data set the researcher noted that the "full-time" and unemployed students would like to have more tutorial classes (Lintvelt 2008:74) during the week, and for all the modules and some even mentioned having lectures every day.

7 The students from Mthatha have to travel to Durban for workshops, while the ones from George/Oudtshoorn have to go to Cape Town. 
these students will have to complete the fourth level over a two-year period. They also complained about the fact that rules are set and changed without calculating the impact on students' lives, and informing them timeously and comprehensively.

\section{CONCLUSION}

Based on the free comments provided by the social work student customers enrolled at the Social Work Department of the University of South Africa), we arrived at the following conclusions:

- Unisa and the Department of Social Work is not simply doing "badly", or only performing "well" - the customers seem both simultaneously satisfied and dissatisfied with similar and different aspects related to service delivery and the quality of services offered by the service industry and the specific service department under scrutiny. Their perceptions on how it is for them to study Social Work at Unisa were mostly experience-based or informed and the experienced satisfaction and/or dissatisfaction can be best described as a short-term attitude based on the evaluation of their experience with an education service supplied (Elliot \& Healy in García-Aracil, 2009:2).

- "Student satisfaction" and "dissatisfaction" are flipsides of the same construct. Furthermore, the features of student satisfaction and/or dissatisfaction in this open and distance learning arena are dependent upon how academic-related and nonacademic related factors or variables (Tessema, Ready \& Yu, 2012:35) are experienced, integrated and how students customers give them meaning.

- In a sense, the customers' unsolicited comments also confirm their continuous belief in Unisa as ODL brand and, while open and distance learning in the context of social work has been labelled as "the province of the others - a minority" (Collins, 2008:424), in this respect Unisa is fulfilling its social mandate in promoting social justice for those seeking social work education but who lack the resources for gaining it through the traditional means (York, 2008:162). Furthermore, and specifically in the context of developing countries, social work through distance education has the potential for meeting one of the most serious and long-standing needs in social services - the need for people to be trained in rural and remote communities and remaining within these communities practising as social workers, and through their practice impacting on the social and economic circumstances in and upliftment of their communities (Callahan \& Wharf, 1989:79; Ojo \& Olakulehin, 2006:4).

\section{A final note}

The following excerpts taken from their comments that speak of their gratitude towards Unisa and the Department of Social Work: "I love the strategy that Unisa uses to reach out to the less-fortunate"; "Thankyou social work department for your empowerment ... thank you for giving us the opportunity to learn social work ..." and "... to be a student in your department ..."; "I appreciate each and every moment with my studies ... thank you once again to have this time with you", and "...I enjoy studying Social Work at 
Unisa ... I can and will recommend this course to anyone anytime with all my confidence. I want to congratulate you for the good work you are doing at Unisa".

\section{REFERENCES}

AKHTAR-DANESH, N., DEHGHAN, M., MORRISON, K.M. \& FONESKA, S. 2011. Parents' perceptions and attitudes on childhood obesity: a q-methodology study. Journal of the American Academy of Nurse Practitioners, 23:67-75.

ALPASLAN, A.H. 2012. "Hellopeter! On: how are they doing?" The perceptions, experiences and recommendations of social work students as customers of an open and distance learning university. Unpublished inaugural lecture. Pretoria: University of South Africa.

ALPASLAN, A.H. 2010a. The coping strategies employed by Unisa's undergraduate students to address the realities experienced with respect to their living conditions in Sunnyside, Tshwane. Social Work/Maatskaplike Werk, 46(1):1-13.

ALPASLAN, A.H. 2010b. The realities related to the living conditions of Unisa's undergraduate students residing in Sunnyside, Tshwane. Social Work/Maatskaplike Werk, 46(2):144-163.

ALPASLAN, N. \& LOMBARD, B. 2011. Studying to become a social worker: examining the motivations of, and challenges facing, students at an open and distance learning university. Social Work/Maatskaplike Werk, 47(4):430-450.

ANGELOPULO, G.C. 2009. Q methodology and the measurement of subjectivity in corporate brand perception. South African Journal of Business Management, 40(3):21-33.

ANGELOPULO, G.C. [In the press]. The drivers of student enrolment and retention: a stakeholder perception analysis in higher education. Perspectives in Education.

ARTINO, A.R. 2008. Motivational beliefs and perceptions of instructional quality: predicting satisfaction with online training. Journal of Computer Assisted Learning, 24: $260-270$.

ASANTE, O. 2008. Distance learners' perception of learner support services. African Journal of Educational Studies in Mathematics and Science, 6:65-73.

ASKELAND, G.A. \& PAYNE, M. 2007. Distance education and international social work education. European Journal of Social Work, 10(2):161-174.

BABBIE, E. \& MOUTON, J. 2011. The practice of social research. 11th impression. Cape Town: Oxford University Press.

BANKS, A.C. \& FAUL, A.C. 2007. Reduction of face-to-face contact hours in foundation research courses: impact on students' knowledge gained and course satisfaction. Social Work Education, 780-793.

BOGDAN, R.C. \& BILKEN, S.K. 1982. Qualitative research for education: an introduction to theory and methods Boston: Allyn and Bacon. 
BOTHA, P. 2011. Obstacles and facilitative opportunities while studying social work with an open and distance learning context. Social Work/Maatskaplike Werk, 47(4):451-462.

BUREAU OF MARKET RESEARCH. 2010. Unisa student registration and campus perception study. Pretoria: Bureau of Market Research, University of South Africa.

CALLAHAN, M \& WHARF, B. 1989. Distance education in social work in Canada. The Journal of Distance Education, 4(2):63-80.

CHANG, S-H. \& SMITH, R.A. 2008. Effectiveness of personal integration in a learnercentred paradigm distance education class based on student satisfaction. Journal of Research on Technology in Education, 40(4):407-426.

CHEN, S-H. 2009. A performance matrix for strategies to improve satisfaction among faculty members in higher education. Quality and Quantity, 45:75-89.

CHRISTIE, A. \& KRUK, E. 1998. Choosing to become a social worker: motives, incentives, concerns and disincentives. Social Work Education, 17(1):21-33.

COLLINS, S. 2008. Open and distance learning in qualifying social work education in Britain and the USA: celebrating diversity and difference? Social Work Education, 27(4):422-439.

CRESWELL, J.W. 2009. Research design: qualitative, quantitative and mixed method approaches $\left(3^{\text {rd }}\right.$ ed). Thousand Oaks, California: Sage Publications.

DONALEK, J.G. \& SOLDWISCH, S. 2004. Demystifying nursing research: an introduction to qualitative research methods. Urologic Nursing, 24(4):354,356.

DZIOPA, F. \& AHREN, K. 2011. A systematic literature review of the applications of Q-techniques and its methodology. Methodology, 7(2):39-55.

ELLINGSEN, I.T., STØRKSEN, I. \& STEPHENS, P. 2010. Q methodology in social work. International Journal of Social Research Methodology, 13(5):395-409.

GALUSHA, J.M. [Sa] Barriers to learning in distance education [Online] Available: http://infrastruction.com/barriers.htm [Accessed: 13/09/2010].

GARCÍA-ARACIL, A. 2009. European graduates' level of satisfaction with higher education. Higher Education, 57:1-21.

GASKELL, A. 2009. Student satisfaction and retention: are they connected? Open Learning, 24(3):193-196.

HAGA, M. \& HEITKAMP, T. 2000. Bringing social work education to the prairie. Journal of Social Work Education, 36(2):309-324.

HIGGS, P. \& VAN WYK, B. 2006. University teaching in South Africa: an African philosophical perspective. New Directions for Higher Education, 133:81-90.

LAWLOR, G.M. 2008. Finding fit between personal context, learning context and work context of students to further practice excellence in social work. Pretoria: University of South Africa. (Unpublished MA Dissertation) 
LINTVELT, R.A. 2008. The personal contexts of undergraduate students in social work at Unisa. Pretoria: University of South Africa. (Unpublished Dissertation)

McBRIEN, B. 2008. Evidence-based care: enhancing the rigour of a qualitative study. British Journal of Nursing, 17(20):1286-1289.

McFALL, J.P. \& FREDDOLINO, P.P. 2000. Quality and comparability in distance field education: lessons learned from comparing three program sites. Journal of Social Work Education, 36(2):293-307.

McPHAIL, B.A. 2004. Setting the record straight: social work is not a female orientated profession. Social Work, 49(2):323-326.

NEUMAN, W.L. 1997. Social research methods: qualitative and quantitative approaches. London: Allyn \& Bacon.

NTHITE, T. 2006. Unisa students march to protest high fees, service. The Pretoria News, 23 September.

OJO, D.O. \& OLAKULEHIN, F.K. 2006. Attitudes and perceptions of students to open and distance learning in Nigeria. International Review of Research in Open and Distance Learning, 7(1):1-10.

OLIARO, L \& TROTTER, C. 2010. A comparison of on-campus and off-campus (or distance) social work education. Australian Social Work, 63(3):329-344.

PEASE, B. 2011. Men in social work: challenging or reproducing an unequal gender regime? Journal of Women and Social Work, 26(4):406-418.

PETIT DIT DARIEL, O., WHARRAD, H. \& WINDLE, R. 2010. Developing Qmethodology to explore staff views toward the use of technology in nurse education. Nurse Researcher, 18(1):58-71.

POTTS, M.K. \& HAGAN, C.B. 2000. Going the distance: using systems theory to design, implement, and evaluate a distance education programme. Journal for Social Work Education, 36(1):131-145.

SAHIN, I. \& SHELLEY, M. 2008. Considering students' perceptions: the distance education student satisfaction model. Educational Technology and Society, 11(3):216223.

SANDER, P., STEVENSON, K., KING, M. \& COATES, D. 2000. University students' expectations of teaching. Studies in Higher Education, 25(3):309-324.

SCHENCK, R. 2009. The socio-economic realities of the social work students of the University of South Africa. Social Work/Maatskaplike Werk, 45(3):299-313.

SHENTON, A.K. 2004. Strategies for ensuring trustworthiness in qualitative research projects. Education for Information, 22:63-75.

SHINEBOURNE, P. \& ADAMS, M. 2007. Q-methodology as a phenomenological research method. Existential Analysis, 18(1):103-116. 
432

TESSEMA, M.T., READY, K. \& YU, W-CW. 2012. Factors affecting colleague students' satisfaction with major curriculum: evidence from nine years of data. International Journal of Humanities and Social Science, 2(2):34-44.

TRICKER, T., RANGECROFT, M. \& LONG, P. 2005. Bridging the gap: an alternative tool for course evaluation. Open Learning, 20(2):185-192.

UNISA HEMIS FIGURES FOR 2011. Retrieved from Unisa Information and Analysis Portal. [Online] Available: http://heda.unisa.ac.za/heda/fsMain.htm. [Accessed: 08/05/2012].

UNISA INTRANET. 2012. myUnisa: Join myUnisa. [Online] Available: https://my.unisa.ac.za/potral/site/!gateway/page/98326718-3ae9-41af-a28d-4931dcf42...

(Accessed: 01/06/2012).

UNIVERSITY OF SOUTH AFRICA. 2008. Self-evaluation portfolio for the HEQC institutional audit. Pretoria: University of South Africa.

WADE, B.L. 2009. Unisa social work students' experiences of trauma: an exploratory study from a person-centred perspective. Pretoria: University of South Africa. (Unpublished Thesis)

WALKER, E.C. \& KELLY, E. 2007. Online instruction: student satisfaction, kudos and pet peeves. The Quarterly Review of Distance Education, 8(4):309-319.

WANG, X. \& YANG, Z. 2010. The effect of brand credibility on consumers' brand purchase intention in emerging economies: the moderating role of brand awareness and brand image. Journal of Global Marketing, 23:177-188.

YORK, R.O. 2008. Comparing three modes of instruction in a graduate social work programme. Journal of Social Work Education, 44(2):157-172.

Prof Nicky Alpaslan, Department of Social Work, Prof George Angelopulo, Department of Communication Science, University of South Africa; Prof Rinie Schenck, Department of Social Work, University of the Western Cape, South Africa. 